\title{
A women's health shop: a unique experiment
}

\section{SUSAN E ROBINSON, M MAUREEN ROBERTS}

\begin{abstract}
A women's health shop in Edinburgh was open for 16 months to provide information and advice in a non-clinical setting and to allow an interchange between informal and formal care in the community. Staffed by nurses, it was visited by 5664 women and 400 men, an average of 24 people each working day. The most popular topics for discussion were women's health problems, and $17 \%$ of women had a personal discussion with the nurse. The shop provided a useful and popular service and offered a practical method of furthering the concept of health promotion.
\end{abstract}

\section{Introduction}

The Edinburgh women's health shop, open from February 1983 until June 1984, generated much interest locally and nationally. It was a centre offering information and advice that, as far as we are aware, was unique in its attempt to provide an accessible nonclinical setting in which women could discuss their health problems.

Our aims were to further the concepts of promotion of health and self care by adopting a non-medical model of health and wellbeing and to offer support to self help groups. We hoped to attract older women and those who did not normally use health services and preventive facilities, and because the shop had developed from an educational programme about breast disease we also aimed to provide information about the early detection of breast cancer. ${ }^{1}$

The Lothian Health Board and all general practitioners in the city were informed about the shop before it opened.

Department of Clinical Surgery, University of Edinburgh

SUSAN E ROBINSON, BA, HV, research coordinator

M MAUREEN ROBERTS, MD, senior lecturer and clinical director, Edinburgh breast screening clinic

Correspondence to: Dr M M Roberts, Edinburgh Breast Screening Clinic, Edinburgh EH11 2JL.

\section{The shop}

The shop was centrally situated in the High Street, which was well served by public transport (figure). Inside, the overall impression was comfortable but not smart. The staff consisted of two health visitors, two clerical

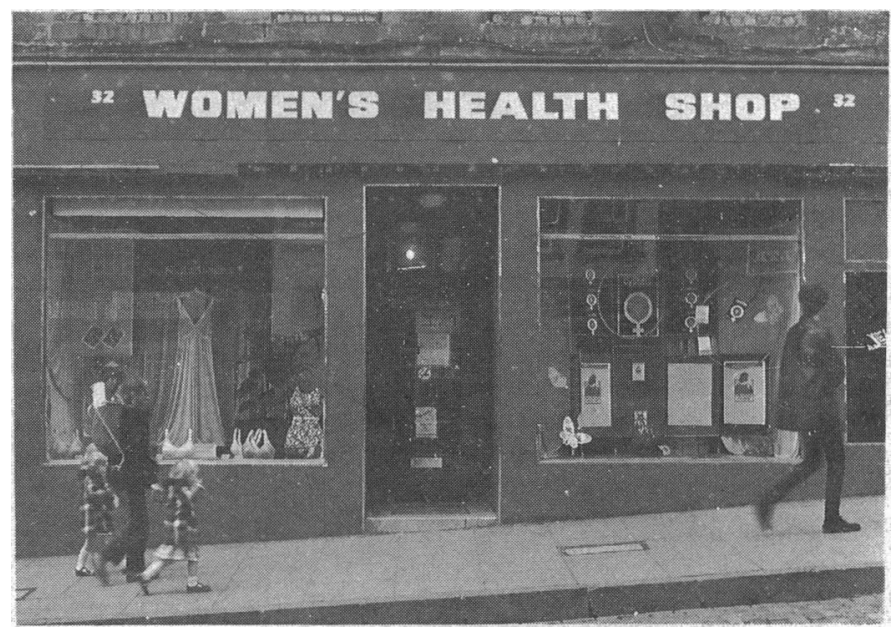

assistants, and a community worker, all of whom worked on a part time basis. The shop was open for three and a half days each week, with two members of staff always present. The total yearly cost was $£ 22000$, including rent, rates, and wages.

A wide range of materials was on display, including books, leaflets and fact sheets, a video, and an exhibition, which changed its theme every few weeks. Any woman making a medical or personal inquiry was seen in a private room by the nurse. For several months fitness tests were offered, combined with a discussion on general wellbeing.

Assessment of the shop-Because the shop was a development project evaluation was kept simple and as unobtrusive as possible. Three methods were used: (1) a daily record was kept of the number of visitors, leaflets distributed, and books sold; (2) questionnaires were given to all visitors to 
complete during two sample periods; and (3) full details were recorded of all interviews with the nurse over 10 weeks, including the age of the woman, problem, duration of visit, and outcome.

\section{Results}

Over 16 months a total of 5564 women and 400 men visited the shop, an average of 24 people each day. Of the 315 women who completed the questionnaires, 116 were classed as having a profession or self employed; 48 as class III non-manual; nine as skilled manual; 14 as unskilled manual; 86 as a housewife, retired, or unemployed; 27 as a student; and 15 as of unknown occupation. Two hundred and eight women said that they came to obtain information about either general health or self help groups, and 38 because they had a specific personal reason. One hundred and twenty nine women were aged under 30,122 were aged $30-50,53$ were aged over 50 , and 11 were of unknown age.

TABLE I-Topics of 176 discussions with nurse April-fune 1984

\begin{tabular}{|c|c|c|c|c|}
\hline & \multicolumn{2}{|c|}{$\begin{array}{l}\text { No of women for whom this } \\
\text { was main concern }\end{array}$} & \multicolumn{2}{|c|}{$\begin{array}{l}\text { Total no of women who } \\
\text { discussed this }\end{array}$} \\
\hline $\begin{array}{l}\text { Menstrual, menopause } \\
\text { Gynaecological } \\
\text { Reproductive } \\
\text { Breast }\end{array}$ & $\begin{array}{l}25 \\
24 \\
11 \\
23\end{array}$ & $47 \%$ & $\begin{array}{l}40 \\
41 \\
23 \\
39\end{array}$ & $35 \%$ \\
\hline General medical & 25 & & 45 & \\
\hline $\begin{array}{l}\text { Mental health } \\
\text { Stress and relaxation } \\
\text { Social and emotional }\end{array}$ & $\begin{array}{l}19 \\
10 \\
13\end{array}$ & $24 \%$ & $\begin{array}{l}27 \\
35 \\
54\end{array}$ & $28 \%$ \\
\hline $\begin{array}{l}\text { Dietary } \\
\text { Other }\end{array}$ & $\begin{array}{r}17 \\
9\end{array}$ & & $\begin{array}{l}41 \\
64\end{array}$ & \\
\hline
\end{tabular}

Almost 30000 leaflets, booklets, and fact sheets were distributed, the most popular being about "women's problems." Altogether 955 women (17\%) had a discussion with the nurse. An analysis of the 176 consultations with the nurse that were well documented showed that the main topics discussed were also related to women's problems (table I). Most interviews (72\%) lasted between 6 and 30 minutes, with half lasting less than 15 minutes, regardless of the woman's age. In addition to giving practical support and advice the discussions with the nurse resulted in referral to other agencies in 127 cases $(72 \%)$, although many of these were to self help groups (table II). In some cases the nurse telephoned a clinic for an appointment-

TABLE II-Outcome of discussions with nurse April-fune 1984. (Figures are numbers of women)

\begin{tabular}{lccccc}
\hline & \multicolumn{5}{c}{ Age (years) } \\
\cline { 2 - 5 } Outcome of discussion & $<30$ & $30-49$ & $>50$ & Unknown & Total \\
\hline None & 8 & 18 & 12 & 11 & 49 \\
Referral to GP & 6 & 9 & 16 & 5 & 36 \\
Referral to well woman clinic & - & 3 & 4 & 4 & 11 \\
Referral to family planning clinic & 10 & 1 & 5 & 1 & 12 \\
Hospital appointment & 1 & 1 & 5 & 9 & 45 \\
Referral to self help group & 4 & 15 & 17 & 2 & 16 \\
Other & - & 4 & 10 & 2 & \\
\hline
\end{tabular}

^Includes referral to social agencies, yoga, physical activities, and a stress management group.

for example, the well woman clinic or a premenstrual tension clinic with which we had established contact. Fifty six women were encouraged to join self help groups, but we have no information on whether this was found to be helpful. Older women were more likely to be referred, and this age bias was highly significant $\left(\chi^{2}=65 \cdot 25, \mathrm{p}<0.0001\right)$.

\section{Discussion}

Over 5600 women visited the shop to obtain information or have a discussion with the nurse about their health. Predictably, the shop took some time to develop, but eventually it was busy and a focal point for much self help activity. As the shop developed from our breast education project ${ }^{1}$ it was natural to think only of women. We recognise, however, that women's health is an important issue, not $\frac{\text { g }}{z}$ only because women are the major users of health resources but $\frac{3}{\Phi}$ because they are also major providers of care. ${ }^{2}$ It is also evident that $\frac{\varrho}{c}$ women are taking a greater interest in their own health. ${ }^{3}$ The new concepts we explored in the shop were the interchange between $\stackrel{\varrho}{\bar{F}}$. informal and formal care in the community ${ }^{4}$ and the breakdown of barriers between professional and other women. By calling it a shop we encouraged women to come as equals.

The opportunity for discussion also allowed a woman to clarify her thoughts and organise her ideas, so that she could then speak with more confidence to her doctor. Theoretically, this could $\stackrel{\stackrel{P}{+}}{+}$ shorten the consultation with a doctor and promote better communication. ${ }^{5}$ It was clear that many women had a strong wish to $\underline{\underline{E}}$ discuss, and obtain information and remedies for, a whole range of $\frac{\overline{\bar{p}}}{\bar{\phi}}$ problems, which some thought would be wasting the doctor's time. $\stackrel{\mathbb{\Phi}}{\Omega}$ The shop, run by health visitors, could provide useful information in this respect, but we recognised the risk of staff acting as $\vec{\sim}$ quasigeneral practitioners rather than maintaining a more preventive? and supportive role.

Partly owing to a lack of funds, the environment was "shabby but $\stackrel{\omega}{\circ}$ friendly," unlike the expensive razzmatazz associated with health $\frac{\partial}{3}$ promotional shops in southern Australia, which appear to be successful in numerical terms (paper presented at Direction in Health Promotional Meeting, Edinburgh 1983). We do not know which type of approach is likely to be more successful in relation to our aims, but our approach might be more appropriate for local culture. To reach a wider cross section of the community we believe G that more community liaison work ${ }^{7}$ is required, with the shop possibly acting as a resource centre.

The shop undoubtedly provided an attractive method of health $\mathrm{N}$ education and promotion, mainly on a one to one basis, reinforced $\subseteq$ by discussions with other women and groups. This is in line with the recommendations of the Health Education Council ${ }^{8}$ and might be a $\overrightarrow{0}$ more effective way of altering behaviour related to health than mass of education campaigns conducted in isolation. ${ }^{9}$ Furthermore, it could $\square$ provide both a suitable environment for attempts to change behaviour related to health and a resource for research into effective health promotion. ${ }^{10}$

We thank the Cancer Research Campaign and the Edinburgh Council of Social Service (William Thyne Trust), who made the study financially possible; the Manpower Services Commission in Edinburgh, which provided part time staff in a community programme; our advisory committee, consisting of Dr Leila Watson, Mr John Davies (Scottish Health Education Group), Ms Yvonne Bostock, and Mr Mike Daube; the staff at the shop, particularly Fiona Bruce, Ann Proudfoot, Margaret McArthur, Joan Mackenzie, Lyn Williams, and Margaret McIntosh; the Scottish Health Education Group and the Lothian Health Board for leaflets, pamphlets, and 3 general help, especially Miss Virginia Moreton and Mr Graham Robertson; Dr Nancy Loudon for her encouragement and help throughout; the many general practitioners who put up posters and encouraged us; Dr Christine West and Dr John Bancroft, who acted as gynaecological advisors and gave public meetings and support; the University of Edinburgh and Dunfermline $N$ College, who loaned us fitness testing equipment; $\mathrm{Mr}$ Tom Steele and $\mathrm{Dr}$ ○ Alison Gordon of Radio Forth; and the many women volunteers who helped, $\frac{D}{O}$ in particular the Reach to Recovery group.

\section{References}

1 Roberts MM, French K, Robinson SE. The Edinburgh breast education project. UICC Technical Reports 1984;77:39-48.

2 Black D, Morris JN, Smith C, Townsend P. Inequalities in health. London: Penguin, 1982:81-3. T

3 McPherson A. Why women's health? In: McPherson A, Anderson A, eds. Women's problems in general practice. Oxford: Oxford University Press, 1983:1-12.

4 Gray JAM. Four box health care. Development in a time of zero growth. Lancet 1983;ii:1185-6.

5 Blaxter M. The causes of disease-women talking. Soc Sci Med 1983;17:59-69.

6 Cartwright A, Anderson R. General practice revisited. London: Tavistock Publications, 1981. Hubley J. Community development and health education. Fournal of the Institute of Health
Education 1980;18:113-20.

8 Gatherer A, Parfit J, Porter E, Vessey M. Is health education effective? London: Health Education Council, 1980.

9 Williams BT. Are public health education campaigns worth while? Br Med J 1984;288:170-1. 을

10 WHO Regional Office for Europe. Health promotion: a discussion document on the concept and principles. Copenhagen: WHO, 1984. (Summary report of working group.) '

(Accepted 2 May 1985) 